\title{
STEM (SCIENCE, TECHNOLOGY, ENGINEERING, AND MATHEMATICS) INOVASI DALAM PEMBELAJARAN VOKASI ERA MERDEKA BELAJAR ABAD 21
}

\author{
SUWARDI \\ SMKN 1 Sekotong, Lombok Barat, NTB \\ E-mail : dhilaardhi@gmail.com
}

\begin{abstract}
ABSTRAK
Pendidikan indonesia masa kini dihadapakan berbagai masalah yaitu kualitas SDM yang dihasilkan dan Penggangguran tamatan. Pengangguran yang paling besar adalah lulusan SMK, berbagai macam dan cara dilakukan untuk mengatasi hal tersebut. Salah satu cara meningkatkan kualitas SDM dengan memberikan inovasi pada proses pembelajaran terutama pada bidang pembelajaran vokasi. Pembelajaran yang dapat diterapkan pada pendidikan vokasi adalah pembelajaran berbasis STEM (Science, Technology, Engineering, and Mathematics). Tujuan penelitian ini adalah untuk memaparkan lebih luas mengenai pembelajaran STEM sebagai pembaruan dalam proses pembelajaran yang dapat diterapkan dalam pembelajaran Vokasi atau SMK. Penelitian ini menggunakan metode kajian literatur terhadap referensi-referensi dan hasil-hasil penelitian yang relevan, yang dilanjutkan dengan diskusi-diskusi kelompok. Hasil dari penelitian ini adalah (1) pembelajaran STEM berhasil diterapkan di dalam maupun luar negeri; (2) Pembelajaran STEM dapat meningkatkan kemampuan berpikir kritis siswa dan menumbuhkan kreativitas siswa; (3) Pembelajaran STEM dapat guru menyiapkan pembelajaran yang lebih menarik dan menantang; (4) Pembelajaran STEM dapat diintegrasikan dengan beberapa model pembelajaran seperti Project Based Learnig, Problem Based Learning maupun model pembelajaran kooperatif; (5) Pembelajaran STEM membuat siswa menatap masa depan lebih maksimal; (6) Pembelajaran STEM sangat cocok digunakan pada pembelajaran abad 21; (7) Pemberlajaran STEM dapat diterapkan dalam Era Merdeka Belajar.
\end{abstract}

Kata kunci: STEM, Inovasi, Pembelajaran, Merdeka belajar,

\section{PENDAHULUAN}

Pendidikan masa kini dihadapkan pada keadaan yang berat yaitu pandemic covid 19, kualitas SDM yang rendah dan pengangguran yang meningkat keadaan ini memacu peserta didik supaya mampu mengimbangi berbagai dinamika perubahan kehidupan yang kompleks. Perubahan yang terjadi berkaitan dengan perkembangan ilmu pengetahuan dan teknologi, social dan budaya serta perubahan dalam nilai moral dan sikap yang dimana akan membuat pergeseran dalam kehidupan bermasyarakat, hal ini tentu berpengaruh terhadap tujuan pendidikan yang telah dirumuskan berdasarkan fungsi dan tujuan pendidikan nasional yang tertuang dalam Undang-Undang Nomor 20 Tahun 2003 Pasal 3 yang berbunyi pendidikan nasional berfungsi mengembangkan kemampuan watak serta peradaban bangsa yang bermartabat dalam rangka mencerdaskan kehidupan bangsa serta mengembangkan potensi peserta didik agar menjadi manusia yang beriman dan bertaqwa kepada Tuhan Yang Maha Esa, berakhlaq mulia, sehat,berilmu, cakap, kreatif, mandiri dan menjadi warga negara yang demokratis serta bertanggung jawab.

Menurut Kepala BPS Suhariyanto (2020):“lulusan Sekolah Menengah Kejuruan (SMK) mendominasi jumlah pengangguran di Indonesia yang mencapai 6,88 juta orang pada Februari 2020. Lulusan SMK menyumbang Tingkat Pengangguran Terbuka (TPT) menurut pendidikan mencapai 8,49\%. "Dilihat dari tingkat pendidikan, TPT Sekolah Menengah Kejuruan (SMK) masih yang paling tinggi di antara tingkat pendidikan lain, yaitu sebesar $8,49 \%$, Sementara, untuk jumlah pengangguran terendah dari pendidikan SD ke bawah sebesar 2,64\%, kemudian SMP 5,02\%, Universitas 5,73\%, SMA 6,77\% dan Diploma I/II/III sebesar 6,76\%.Namun, perkembangan tren pengangguran lulusan SMK mengalami penurunan 
dari tahun 2018 hingga 2020 Tercatat, angka pengangguran lulusan SMK mencapai 8,92\% pada Februari 2018, kemudian turun menjadi 8,63\% pada Februari 2019. Saat ini, jumlah angkatan kerja pada Februari 2020 sebanyak 137,91 juta orang, naik 1,73 juta orang dibanding Februari 2019. Berbeda dengan naiknya jumlah angkatan kerja, Tingkat Partisipasi Angkatan Kerja (TPAK) turun sebesar 0,15\%."

Salah satu cara untuk menghasilkan SDM yang berkualitas adalah dengan membenahi sistem pendidikan. Pendidikan merupakan salah satu aspek terpenting dalam kehidupan guna membentuk sumber daya manusia yang berkualitas dan mampu mengikuti arus perkembangan jaman yang semakin maju. Selain itu pendidikan merupakan salah satu sektor penting dan dominan dalam menentukan maju mundurnya suatu bangsa. Pendidikan dalam Nana Sudjana (1994) memegang peranan penting dalam meningkatkan kualitas sumber daya manusia, terutama dalam proses pembangunan nasional. Oleh karena itu upaya peningkatan mutu pendidikan di sekolah merupakan strategi dalam meningkatkan sumber daya manusia. Pendidikan sebagai wahana utama pembangunan sumber daya manusia berperan dalam mengembangkan peserta didik menjadi sumber yang produktif dan memiliki kemampuan professional dalam meningkatkan mutu kehidupan berbangsa dan bernegara. Disamping itu pendidikan adalah proses budaya untuk meningkatkan hatkat dan martabat manusia, melakui proses yang panjang dan berlangsung sepanjang hayat. Menurut Bruner dalam Dina Indriana menyatakan bahwa tujuan pendidikan adalah untuk membebaskan masyarakat dan membantu para siswa dalam mengembangkan potensi mereka secara penuh.

Salah satu pembelajaran yang dapat diterapkan untuk mendukung tujuan pendidikan vokasi adalah pembelajaran STEM. STEM merupakan akronim dari science, technology, engineering, dan mathematics. Istilah ini pertama kali diluncurkan oleh National Science Foundation (NSF) Amerika Serikat (AS) pada tahun 1990 sebagai tema gerakan reformasi pendidikan untuk menumbuhkan angkatan kerja bidang-bidang STEM, serta mengembangkan warga negara yang melek STEM (STEM literate), serta meningkatkan daya saing global Amerika Serikat dalam inovasi iptek (Hanover Research, 2011). Menurut Kamus Besar Bahasa Indonesia (KBBI) empat bidang ilmu tersebut memiliki pengertian yang berbeda, yaitu: (1) sains, merupakan pengetahuan sitematis yang diperoleh dari suatu observasi, penelitian, dan uji coba yang mengarah pada prinsip sesuatu yang sedang diselidiki, dan dipelajari; (2) teknologi, merupakan keseluruhan sarana untuk menyediakan barang-barang yang diperlukan bagi kelangsungan dan kenyamanan hidup manusia; (3) teknik, merupakan pendekatan atau siSTEM untuk mengerjakan sesuatu; dan (4) matematika, merupakan ilmu tentang bilangan, hubungan antara bilangan, dan prosedur operasional yang digunakan dalam penyelesaian masalah mengenai bilangan.

Gerakan reformasi pendidikan STEM ini didorong oleh laporan dari berbagai studi yang menunjukkan terjadinya kekurangan kandidat untuk mengisi lapangan kerja di bidang STEM, tingkat literasi sains, serta posisi capaian siswa sekolah menengah AS dalamTIMSS dan PISA (Roberts, 2012). Selain itu, AS juga menyadari pertumbuhan ekonominya berjalan secara datar dan akan tersaingi oleh China dan India, karena perkembangan sains, teknologi, enginering dan matematika dari kedua negara tersebut yang lebih maju.

Berdasarkan survey yang dilakukan bahwa pertumbuhan lapangan pekerjaan di bidang STEM diproyeksikan lebih tinggi dibandingkan dengan lapangan pekerjaan nonSTEM. Selain itu, dari segi penghargaan, pekerjaan di bidang STEM akan memberikan income yang juga lebih tinggi dibandingkan dengan bidang pekerjaan non-STEM. 


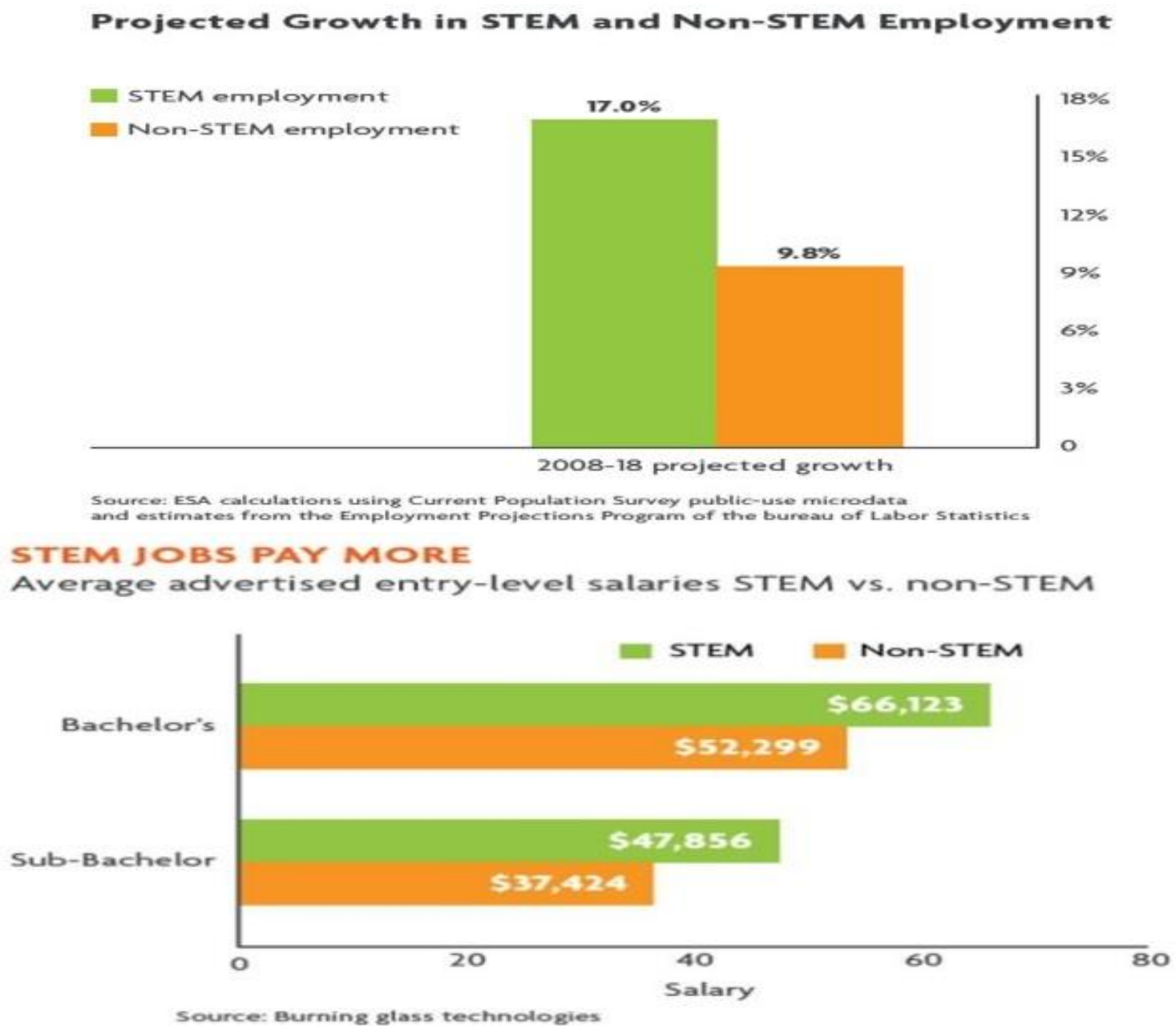

\section{Gambar 1. Proyeksi pertumbuhan pekerjaan STEM dan non-STEM (kiri) serta perbandingan income dari kedua jenis bidang tersebut (kanan)}

Pendidikan STEM adalah pendekatan dalam pendidikan di mana Sains, Teknologi, Teknik, Matematika terintegrasi dengan proses pendidikan berfokus pada pemecahan masalah dalam kehidupan sehari-hari yang nyata serta dalam kehidupan profesional. Pendidikan STEM menunjukkan kepada peserta didik bagaimana konsep, prinsip, teknik sains, teknologi, teknik dan matematika (STEM) digunakan secara terintegrasi untuk mengembangkan produk, proses, dan sistem yang bermanfaat bagi kehidupan manusia. Sebagai komponen dari STEM, sains adalah kajian tentang fenomena alam yang melibatkan observasi dan pengukuran sebagai wahana untuk menjelaskan secara obyektif alam yang selalu berubah. Terdapat beberapa domain utama dari sains pada jenjang pendidikan dasar dan menengah, yakni fisika, biologi, kimia, se rta ilmu pengetahuan bumi dan antariksa (IPBA). Teknologi merujuk pada inovasiinovasi manusia yang digunakan untuk memodifikasi alam agar memenuhi kebutuhan dan keinginan manusia, sehingga membuat kehidupan lebih nyaman dan lebih aman. Teknologi menjadikan manusia dapat melakukan perjalanan secara cepat, berkomunikasi langsung dengan orang di tempat yang berjauhan, memperoleh makanan sehat, dan alat-alat keselamatan. Rekayasa (engineering) merupakan pengetahuan dan keterampilan untuk memperoleh dan mengaplikasikan pengetahuan ilmiah, ekonomi, sosial, serta praktis untuk mendesain dan mengkonstruksi mesin, peralatan, sistem, material, dan proses yang bermanfaat bagi manusia secara ekonomis dan ramah lingkungan. Selanjutnya, matematika berkenaan dengan pola-pola dan hubungan-hubungan, dan menyediakan bahasa untuk teknologi, sains, dan rekayasa. 
Penggunaan pendekatan STEM dalam bidang pendidikan memiliki tujuan untuk mempersiapkan peserta didik agar dapat bersaing dan siap untuk bekerja sesuai bidang yang ditekuninya. Penelitian yang dilakukan oleh lembaga penelitian Hannover (2011) menunjukkan bahwa tujuan utama dari STEM Education adalah sebuah usaha untuk menunjukkan pengetahuan yang bersifat holistik antara subjek STEM. Dalam konteks pendidikan dasar dan menengah, pendidikan STEM bertujuan mengembangkan peserta didik yang STEM literate (Bybee, 2013), dengan rincian sebagai berikut.

1. Memiliki pengetahuan, sikap, dan keterampilan untuk mengidentifikasi pertanyaan dan masalah dalam situasi kehidupannya, menjelaskan fenomena alam, mendesain, serta menarik kesimpulan berdasar bukti mengenai isu-isu terkait STEM;

2. Memahami karakteristik khusus disiplin STEM sebagai bentuk-bentuk pengetahuan, penyelidikan, dan desain yang digagas manusia;

3. Memiliki kesadaran bagaimana disiplindisiplin STEM membentuk lingkungan material, intelektual dan kultural;

4. Memiliki keinginan untuk terlibat dalam kajian isu-isu terkait STEM (misalnya efisiensi energi, kualitas lingkungan, keterbatasan sumberdaya alam) sebagai warga negara yang konstruktif, peduli, serta reflektif dengan menggunakan gagasan-gagasan sains, teknologi, rekayasa, dan matematika;

Sedangkan jika kita lihat tujuan dan hasil dari pendidikan STEM bagi siswa dan pendidik dapat kita lihat pada tabel di bawah ini.

Tabel. 1 Tujuan dan hasil pendidikan STEM

\begin{tabular}{|c|c|c|}
\hline & Tujuan Pendidikan STEM & Hasil Pendidikan STEM \\
\hline Bagi Siswa & $\begin{array}{l}\text { l Literasi STEM } \\
>\text { Kompetensi abad } 21 \\
>\text { Kesiapan Tenaga Kerja STEM } \\
>\text { Minat dan keterlibatan } \\
>\text { Membuat koneksi }\end{array}$ & $\begin{array}{l}>\text { Belajar dan Berprestasi } \\
>\text { Kompetensi abad } 21 \\
>\text { Ketekunan dan kegigihan belajar dalam } \\
\text { meningkatkan prestasi } \\
>\text { Pekerjaan yang berhubungan dengan } \\
\text { STEM } \\
>\text { Meningkatkan minat STEM } \\
>\text { Pengembangan identitas STEM } \\
\\
\square \text { Kemampuan untuk membuat koneksi di } \\
\quad \text { antara disiplin STEM }\end{array}$ \\
\hline $\begin{array}{l}\text { Bagi } \\
\text { Pendidik }\end{array}$ & 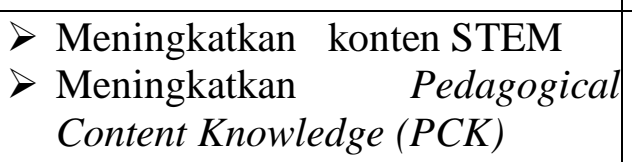 & $\begin{array}{l}\text { Perubahan dalam praktik } \\
>\text { Peningkatan konten STEM dan PCK }\end{array}$ \\
\hline
\end{tabular}

Pendidikan STEM memberi pendidik peluang untuk menunjukkan kepada peserta didik betapa konsep, prinsip, dan teknik dari STEM digunakan secara terintegrasi dalam pengembangan produk, proses, dan sistem yang digunakan dalam kehidupan sehari-hari mereka. Oleh karena itu, definisi pendidikan STEM diadopsi sebagai pendekatan interdisiplin pada pembelajaran (Reeve, 2013). Dalam pembelajaran berbasis STEM peserta didik menggunakan sains, teknologi, rekayasa, dan matematika dalam konteks nyata yang menghubungkan sekolah, dunia kerja, dan dunia global guna mengembangkan literasi STEM yang memungkinkan peserta didik mampu bersaing dalam abad ke-21. 
Stohlmann et al (2012) mengidentifikasi 4 faktor yang perlu dipertimbangkan bagi pendidik sehingga pembelajaran STEM dapat berlangsung dengan sukses. Keempat faktor tersebut dapat dilihat pada gambar di bawah.

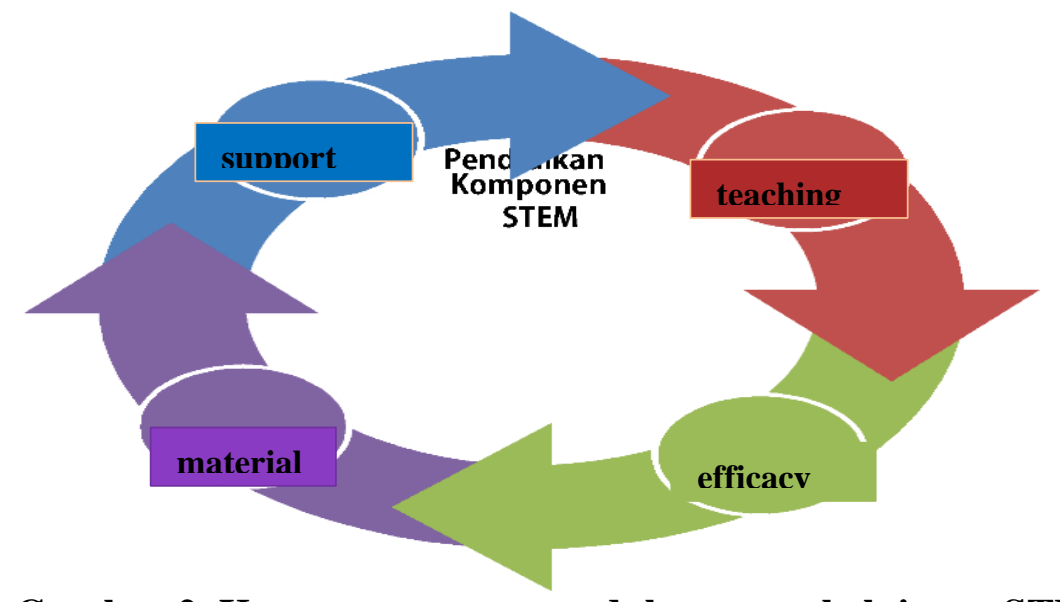

\section{Gambar 2. Komponen yang mendukung pembelajaran STEM}

Aspek support atau dukungan berkaitan dengan berbagai kegiatan yang dapat mendukung pendidik dalam menerapkan pembelajaran STEM seperti keikutsertaan dalam pelatihan yang relevan, kolaborasi dengan sekolah atau institusi lain seperti universitas atau industri, serta adanya kesempatan untuk berkolaborasi dengan guru-guru lain dalam sekolah yang sama. Aspek teaching atau pembelajaran menitikberatkan pada persiapan pembelajaran dan implementasi pembelajaran di kelas. Aspek efficacy terkait dengan kepercayaan diri pendidik dalam mengimplementasikan pembelajaran STEM yang dapat dipengaruhi oleh tingkat penguasaan materi pembelajaran serta pedagogik, serta komitmennya dalam melaksanakan pembelajaran. Aspek materials terkait dengan kesiapan sarana dan prasarana penunjang pembelajaran.

\section{METODE PENELITIAN}

Penelitian ini berusaha mengetahui, memahami dan mendeskripsikan pembelajaran STEM pada abad 21 era merdeka belajar. Dalam hal ini, peneliti melakukan penelitian dengan cara penelitian deskriptif dengan menggunakan pendekatan kualitatif. Menurut Bogdan dan Taylor (1992:21-22), penelitian kualitatif adalah salah satu prosedur penelitian yang menghasilkan data deskriptif berupa ucapan atau tulisan dan perilaku orang-orang yang diamati. Adapun teknik pengumpulan data yang digunakan pada penelitian ini disesuaikan dengan tujuan dari penelitian ini yaitu studi pustaka (studi literatur). Studi kepustakaan berkaitan dengan kajian teoritis dan referensi lain yang berkaitan dengan nilai, budaya dan norma yang berkembang pada situasi sosial yang diteliti, selain itu studi kepustakaan sangat penting dalam melakukan penelitian, hal ini dikarenakan penelitian tidak akan lepas dari literatur-literatur Ilmiah (Sugiyono, 2007: 291). Sumber riset pustaka pada penelitian ini diambil dari buku cetak, jurnal ilmiah, dan artikel berita online yang memuat informasi mengenai pembelajaran STEM di abad 21 dalam era merdeka belajar.

\section{HASIL DAN PEMBAHASAN}

Penelitian STEM sudah banyak dilakukan di dalam negeri maupun di luar negeri dimana hasilnya sangat baik. Dalam penelitian yang berjudul Introducing STEM Education: Implication for Educating Our Teacher for the Age of Inovation, hasil penelitiannya bahwa Pembelajaran STEM dapat mengubah konsep model pengajaran baku menjadi pembelajaran yang kreatif, inovatif dan menekankan pada pemecahan masalah (Corlu \& Capraro, 2014). Penelitian tersebut juga sangat mendukung penerapan kurikulum saat ini (kurikulum 2013 revisi) yang menekankan pada keaktifan siswa dalam kelas, membuka wawasan dan kreatifitasan siswa dengan berfokus pada interaksi matamatika 
dan sains STEM menekankan pentingnya empat bidang ilmu pengetahuan (sains, teknologi, teknik, dan matematika) untuk memecahkan suatu permasalahan. Penelitian yang dilakukan di Indonesia, salah satu contoh adalah penelitian yang tentang inovasi dalam pembelajaran sains yang menyimpulkan bahwa pembelajaran STEM dapat dijadikan acuan sebuah inovasi pembelajaran untuk membangun keterampilan abad 21 yaitu keterampilan 4C (Communication, Collaboration. Critical Thinking and problem solving, dan Creative and Innovative) dalam masa merdeka belajar (Permanasari: 2016).

Penelitian yang berjudul STEM integration in sixth grade: desligning and contructing paper bridges menyimpulkan bahwa pembelajaran ini mendapatkan respon yang posistif dari siswa, dapat dilihat dalam siswa membangun jembatan dengan kertas yang kerjanya optimal (English \& King, 2019). Dengan hasil tersebut disimpulkan STEM dapat meningkatkan kemampuan siswa terhadap merencanakan, merancang, merefleksi, membangun dan mendesain ulang sebuah proyek yang ditugaskan. Penelitian berjudul STEM education to fulfil the 21st century demand membahas STEM berdasarkan beberapa studi literatur dan dapat disimpulkan pembelajaran STEM dapat diterapkan di dalam dan luar negeri dan sesuai dengan perkembangan abad 21 (Rifandi \& Rahmi, 2019), ini juga menandai bahwa siswa mampu bersaing dan berkompetensi dalam bidang yang diminati. Dalam penelitian yang berjudul STEM education: the potential of technology education menyimpulkan STEM dapat dijadikan alternatif untuk mengatasi hambatan dan tantangan dalam bidang teknologi pendidikan serta memberikan efek bagi siswa dapat (Wells, 2019).

Temuan lain tentang pembelajaran STEM dalam Ismayani (2016 : 264-272) yaitu tingkat kreativitas siswa smk yang dipengaruhi penerapan STEM project based learning dari penelitian tersebut menyimpulkan bahwa rerata pencapaian kemampuan berpikir kreatitf siswa setelah pembelajaran STEM PjBL meningkat sangat signifikan dibanding sebelum mengikuti pembelajaran dengan STEM PjBL, dan melalui uji analisis yang dilakukan, menemukan perbedaan pencapaian kemampuan sebelum dan setelah pembelajaran berbeda secara signifikan, artinya ketika pembelajaran STEM yang diintegrasikan dengan model PjBL dilakukan secara efektif maka dapat meningkatkan kreativitas siswa secara signifikan. Sejalan dengan temuan tersebut Lou et al, (2017: 2387-2404) dalam penelitian yang berjudul a study of creativity in cac2 steamship-derived STEM project-based learning menunjukan hasil bahwa pengajaran utama dari lima tahap pembelajaran berbasis proyek STEM yang terdiri dari persiapan, implementasi, presentasi, evaluasi, dan koreksi dapat meningkatkan kreativitas siswa. Temuan tersebut mempertegas apabila pembelajaran STEM dapat dipersiapkan dengan baik dari tahap persiapan sampai evaluasi dan koreksi, kreativitas dari siswa dapat meningkat dengan signifikan. Penelitian lain tentang STEM yang dapat meningkat kreativitas siswa juga mendapatkan hasil positif hasil peneltian tersebut menunjukkan pembelajaran berbasis STEM yang diintegrasikan dengan model PjBL mampu meningkatkan keterampilan berpikir kreatif siswa dan mencapai kategori tinggi (Kristiani et al, 2017: 266-274) Hal tersebut sejalan dengan penelitian yang berjudul integrated STEM education: a sySTEMatic review of intructional practices in secondary education menjelaskan bahwa untuk mendapat hasil yang maksimal STEM harus diintegrasikan dengan model pembelajaran lain, salah satunya yaitu: pembelajaran yang berpusat pada masalah, pembelajaran berbasis inkuiri, pembelajaran berbasis desain, maupun pembelajaran kooperatif (Thibaut et al, 2018). Ketiga penelitian tersebut menjelaskan pembelajaran STEM yang diintegrasikan dengan model pembelajaran dapat meningkatkan kreativitas siswa dengan sangat signifikan apabila direncanakan sebaik mungkin sesuai tahapan dalam pembelajaran STEM.

Afriana et al, (2016: 202-212) mengungkapkan bahwa penelitian pembelajaran STEM juga dapat diintegrasikan dalam model pembelajaran kooperatif, Problem Based Learning (PBL), Project Based Learning (PjBL) maupun model pembelajaran lainnya. Sejalan dengan penelitian tersebut penelitian tentang project based learning terintegrasi STEM yang ditinjau dari gender untuk meningkatkan literasi sains siswa juga menunjukkan hasil bahwa literasi 
sains antara kelas perempuan dan kelas laki-laki berbeda tidak signifikan, dan tanggapan siswa baik itu siswa laki-laki maupun siswa perempuan menunjukkan seluruh siswa menyatakan senang dengan pembelajaran STEM dan memperoleh pengalaman ketika mengikuti tahapan-tahapan pembelajaran sehingga menimbulkan motivasi dan minat dalam belajar. Hasil tersebut menunjukkan bahwa pengimplementasian pembelajaran STEM dapat meningkatkan kemampuan belajar siswa, dengan pembelajaran STEM siswa dapat meningkatkan skill multipresentasi dan juga dapat meningkatkan kemampuan berpikir kritis dan tidak terpengaruh dengan gender, baik itu laki-laki maupun perempuan.

Penelitian di Indonesia mengenai STEM ini memperlihatkan hasil yang baik dan kelas yang menggunakan pendekatan STEM ini memilki skill multipresentasi lebih baik secara signifikan dibandingkan dengan siswa yang belajar menggunakan pendekatan saintifik. Hasil ini sejalan dengan penelitian yang berjudul the implementation of science, technology, engineering, and mathematics (STEM) approach for improving multiple-representation skill of senior high school student on newton's law about motion (Mulyana et al, 2018: 69-75). Dalam kurikulum 2013 lebih menekankan pada pendekatan saintifik tetapi dalam penelitian di atas menunjukkan pendekatan STEM mampu meningkatkan skill multipresentasi siswa dengan signifikan. Dengan kata lain dalam penerapan kurikulum 2013 disamping menggunakan pendekatan saintifik dapat juga menggunakan pendekatan STEM.

Dalam Rahmadhani \& Wahyuni (2018: 129-140) Penerapan STEM juga dapat dilakukan pada perguruan tinggi, dimana pendekatan STEM ini dapat meningkatkan kemampuan pemahaman konsep dan minat bagi mahasiswa. Artinya adalah pada jejnajng perguruan tinggi pendekatan STEM dapat diterapkan dengan baik dan terjadi interaksi antara kemampuan awal dengan pendekatan STEM dalam mempengaruhi pemahaman konsep akan tetapi tidak dengan minat mahasiswa. Artinya jenjang perguruan tinggi mahasiswa tidak terlalu berminat dengan pembelajaran STEM, tetapi STEM dapat meningkatkan pemahaman konsep mahasiswa ketika mengikuti pembelajaran.

Menurut beberapa penelitian yang sudah dilakukan oleh peneliti baik itu yang diluar negeri atau dalam negeri menunjukkan metode pembelajaran STEM mendapat apresiasi baik dan positif. Pembelajaran STEM jika digabungkan dengan model pembelajaran lain seperi $\mathrm{PjBL}$ maupun $\mathrm{PBL}$ dapat menumbuhkan hal positif seperti meningkatkan berpikir kritis siswa, kreatifitas, komunikasi dan kerjasama yang dibutuhkan dalam abad 21 ini. Di Indonesia penerapan walaupun belum ada penelitian secara khusus, tetapi pembelajaran STEM ini dapat dilaksanakan dengan baik pembelajaran vokasi karena melihat dari berhasilnya diterapkan pada pembelajaran sains dan matematika. Hal ini tentu dapat meningkatkan kualitas lulusan SMK, sehingga pengangguran di Indonesia dapat berkurang. Beberapa forum diskusi yang dilakukan beberapa kalangan merekomendasikan yaitu: (1) perlu dilakukan penelitian tentang STEM, pada bidang vokasi oleh dosen, guru atau lembaga terkait; (2) perlu dibuat kerja sama antara lembaga pendidikan yang bergerak dalam bidang vokasi dengan lembaga yang sudah sering melakukan pembelajaran STEM, sehingga dapat memberikan pelatihan kepada guru maupun dosen vokasi; (3) perlu dibuat format kusus dari awal pengenalan STEM sampai evaluasi untuk mengukur keberhasilan STEM yang diterapkan dalam bidang vokasi.

\section{KESIMPULAN}

Berdasarkan kajian dari beberapa literatur dan referensi yang digunakan dapat ditarik kesimpulan sebagai berikut:

1. Pembelajaran STEM berhasil diterapkan di dalam maupun luar negeri;

2. Pembelajaran STEM dapat meningkatkan kemampuan berpikir kritis siswa dan menumbuhkan kreativitas siswa;

3. Pembelajaran STEM dapat guru menyiapkan pembelajaran yang lebih menarik dan menantang;

4. Pembelajaran STEM dapat diintegrasikan dengan beberapa model pembelajaran seperti Project Based Learnig, Problem Based Learning maupun model pembelajaran kooperatif; 
5. Pembelajaran STEM membuat siswa menatap masa depan lebih maksimal;

6. Pembelajaran STEM sangat cocok digunakan pada pembelajaran abad 21;

7. Pemberlajaran STEM dapat diterapkan dalam Era Merdeka Belajar

Pembelajaran STEM dapat diterapkan dalam beberapa disiplin ilmu khususnya dalam bidang sains dan matematika. Atas dasar itu sudah saatnya pembelajaran STEM juga diterapkan pada pembelajaran vokasi (teknik), dimana pembelajaran vokasi yang mengedepankan praktik dan pemecahan masalah yang berhubungan dengan kegiatan sehari -hari, tentunya dengan pembelajaran STEM lebih mudah menyelesaikan permasalahan tersebut dan membuat siswa lebih memahami apa yang mereka pelajari. Harapan kedepan pembelajaran STEM dapat diaplikasikan secara luas dipendidikan vokasi yang berguna bagi guru dan siswa serta dapat diakomodir oleh pendidikan abad 21 dan era merdeka belajar.

\section{DAFTAR PUSTAKA}

Afriana, J., Permanasari, A., \& Fitriani, A. (2016). Penerapan Project Based Learning terintegrasi STEM untuk meningkatkan literasi sains siswa ditinjau dari gender. Jurnal Inovasi Pendidikan IPA, 2(2), 202-212.

Avery, Z. K., \& Reeve, E. M. (2013). Developing effective STEM professional development programs. Journal of Technology Education, 25(1), hlm. 55- 69.

Bogdan, Robert dan Steven Taylor. 1992. Pengantar Metode Kualitatif. Surabaya: Usaha Nasional.

Corlu, M. S., Capraro, R. M., \& Capraro, M. M. (2014). Introducing STEM education: Implications for educating our teachers in the age of innovation. Eğitim ve Bilim, 39(171), 74-85.

Dina Indriana. Mengenal Ragam Gaya Pembelajaran Efektif. (Yogyakarta: Diva Press, 2011), hal. 196.

English, L. D., \& King, D. (2019). STEM integration in sixth grade: desligning and constructing paper bridges. International Journal of Science and Mathematics Education, 17(5), 863-884. Hanover Research (2011). K-12 STEM education overview.

Ismayani, A. (2016). Pengaruh penerapan STEM project-based learning terhadap kreativitas matematis siswa SMK. Indonesian Digital Journal of Mathematics and Education, 3(4), 264-272.

Kamus Besar Bahasa Indonesia (KBBI) Nasional, D. P. (2008). Kamus besar bahasa Indonesia.

Kristiani, K. D., Mayasari, T., \& Kurniadi, E. (2017, August). Pengaruh pembelajaran STEMPjBL terhadap keterampilan berpikir kreatif. In Prosiding SNPF (Seminar Nasional Pendidikan Fisika) (pp. 266-274).

Lou, S. J., Chou, Y. C., Shih, R. C., \& Chung, C. C. (2017). A study of creativity in CaC2 steamship-derived STEM project-based learning. Eurasia Journal of Mathematics, Science and Technology Education, 13(6), 2387-2404.

Mulyana, K. M., Abdurrahman, A., \& Rosidin, U. (2018). The implementation of science, technology, engineering, and mathematics (STEM) approach for improving multiplerepresentation skill of senior high school student on newton's law about motion. Jurnal Pendidikan Fisika, 7(2), 69-75.

Nana Sudjana. Pembinaan dan Pengembangan Kurikulum di Sekolah. (Bandung: Sinar Baru Algensindo, 1994),

Permanasari, A. (2016). STEM education: inovasi dalam pembelajaran sains. In Prosiding.

Rahmadhani, E., \& Wahyuni, S. (2018). Kemampuan Pemahaman Konsep dan Minat Mahasiswa dengan Pendekatan STEM (Science, Technology, Enginnering, Mathematics). Prosiding SENAMKU, 1, 129-140. 
Rifandi, R., \& Rahmi, Y. L. (2019, October). STEM education to fulfil the 21st century demand: a literature review. In Journal of Physics: Conference Series (Vol. 1317, No. 1, p. 012208). IOP Publishing.

Roberts, A. (2012). A justification for STEM education. Technology and Engineering Teacher, 74(8), 1-5. Roberts, A. \& Cantu, D. (2012). Applying STEM instructional strategies to design and technology curriculum. Technology Education in the 21st Century, (73), 111- 118.

Stohlmann, M., Moore, T.J \& Roehrig, G.H. (2012). Conciderations for Teaching Integrated STEM Education. Journal of Pre-College Engineering Education Research (J-PEER), 2(1), hlm. 28-33. Diakses melalui http;//dx.doi.org/10.5703/1288284314653.

Sugiyono. (2007). Metode Penelitian Kuantitatif Kualitatif dan R\&D. Bandung: Alfabeta.

Suhariyanto (2020) Angka pengangguran di Indonesia. Diakses di https://economy.okezone.com/read/2020/05/05/320/2209470/6-88-juta-orangnganggur-paling-banyak-lulusan smk.

Thibaut, L., Ceuppens, S., De Loof, H., De Meester, J., Goovaerts, L., Struyf, A., ... \& Hellinckx, L. (2018). Integrated STEM education: A sySTEMatic review of instructional practices in secondary education. European Journal of STEM Education, 3(1), 2.

UU no 20 tahun 2003 tentang sistem pendidikan nasional.

Wells, J. G. (2019). STEM education: The potential of technology education. Council on Technology and Engineering Teacher Education. 